\title{
Analysis of Chinese Traditional Art Education Theory
}

\author{
Wenyong Xue \\ Nanyang Institute of Science and Engineering, Nanyang, Henan, 473004
}

Keywords: Traditional Art Education, Education Theory, Modern Teaching Skill.

\begin{abstract}
Before the emergence of China's modern school education, the rich traditional art education resources as an important way of Chinese art inherited, along with the Chinese nation for thousands of years old and deep traditional culture. Artists have accumulated rich experience in art education, and the outstanding theories of these traditional art education still shine in today's school art education in the history of ancient Chinese art.
\end{abstract}

\section{Introduction}

In recent years, despite the strength of art education theory and lineup is still inferior to other art disciplines, but its status is a significant increase in fact. The field of art education is increasingly showing its own powerful power and important value, not only more and more attention, but also began to selectively accept the relevant Western education and art education theory of outstanding achievements. Western modern and postmodernist education methods and strategies, so that domestic educators are enlightened, and deep or shallow use of the current art education practice, so that art education to participate in contemporary art, contemporary cultural construction of active factors. In the study of the construction of fine arts and the practice of contemporary art education, the author chooses the basic research of traditional Chinese art education theory. The idea of the introduction of historical archives, master bone marrow, abstract Gu Shen, in the ancient art books, education and Western modern psychology, educational thought of the profound and unique theoretical space in mining, demonstrate the essence of Chinese art education theory the purpose is to analyze the traditional art education theory and the basic characteristics of the traditional art education, to provide a reference for the current practice of Chinese art education, and to make the construction of the art education discipline for the start and construction. force.

\section{Excellent Theory of Chinese Traditional Fine Arts Education}

China is a country with a long tradition of teachers, 2500 years ago, Confucius and their various subjects to the world to "all, and security" as their responsibility, love life loyalty, running call sign, by sermons, for later generations set up for The moment and spirit of the teacher. Many of the ancient Chinese painters are lifelong self-cultivation, model, unreasonable wealth as dirt, in the history of the long painting in the formation of the benefits of the world's standard and selfless desire to love the spirit of tradition. Teacher love, refers to the teacher on the students conscious, innocent, persistent, selfless, universal love. On the surface, it is a kind of beautiful emotion of the teacher to the student, is a rare teaching method and education art, and in essence is the teacher through the rational cultivation of the lofty sense of mission and a high sense of responsibility. In addition to the ancient Chinese painters continue to accumulate experience in painting, in the art of excellence, most of life dedicated to the cause of painting education, depending on the cultivation of painting as their responsibility. Their teacher love the spirit into a strong personality strength, probation education students and the world. In today's art education, this division of the spirit of love and morality is very worthy of the glorious.

In the history of painting, with four kings and their followers as the representative of some painters, very stressed that the traces of the ancients. Qing Dynasty landscape painter Wang Shimin, his grandfather Wang Xijie (Wanli had served as the first auxiliary, the equivalent of prime minister) 
to cultivate this love Sun, Dong Qichang teach him to paint. Dong guided him from the copy to start, let him observe the home of many Song and Yuan paintings, so progress quickly. Wang Shiming's landscape, with Huang Gongwang as the case, the early works and Dong Qichang's painting looks similar to the middle school gradually formed vigorous and vigorous personal style. He is a good art educator, the early Qing Dynasty painter Wang halo, Wu Li and Shou Shou Ping are from his door. He was only thirsty, reward the spirit of backward, in the painting to win the noble prestige, become a master of the early Qing Dynasty. Another painter Wang Jiai Ming Ming Dynasty famous scholar Wang Shizhen's great-grandson. He and the painter Wang Shiming with the same way, often with the painting art. He has also consulted to Dong Qichang painting, so he and Wang Shimin believe in the "North-South", but he was not hesitant to a public, and Dong, giant for the case, and Song and Yuan Zhujia painting, Style than Wang Shiming more skill than Wang deep. Wang Yuan Qi (1) is the early painter Wang Shimin's son, Wang's son. He hugged his childhood painting landscape, one day he mocked his grandfather's strokes painted a landscape attached to the wall of the book, Wang Shimin see doubts: this painting when I painted? When he knows is the grandson painted, Greatly surprised that the child will draw more than the future of their own water (see "the DPRK painting collection"), so let him read the book, one side to teach him research reference. Plus the old painter Wang Jian, three uncle father from time to time pointing, and have the opportunity to work together with Wang generation of art, for the future development laid a good foundation. The above examples fully prove the importance of intercourse on Chinese painting.

\section{The Modern Value of Chinese Traditional Art Education Theory}

On the imitation of the point of view, in the West has a long history of origin. Ancient Greek philosopher Heraclitus originally proposed a "art imitation of nature" in one of his fragments. Plato also believes that painting is only an imitation of the appearance of things. Aristotle sees imitation as a human instinct, and imitation can bring great happiness. People generally have imitation of nature, through imitation to get action and methods to express the natural and their own ideas and emotions. It is in line with the "imitation of the human nature" of the educational content of the ancient Chinese mentoring and inheriting the importance of the copy and the important way of learning in the art education mode.

"Style" (style) from the Latin word "stilus", "stilus" refers to the Roman a writing instrument. "Style" can be used to express a writer's writing style. The analysis of the various possibilities and categories of style in Greek and Roman rhetoric teachers is still the most exquisite analysis. The so-called decent principle, that is, style to meet the occasion of the principle of time, far-reaching impact. In accordance with the views of Xixiro (iceeor), too much to pursue the effect will cause a hollow contrived, lack of strength style. Only the greatest model ("classical" writer) who continually studies the style can keep the style pure. (2) traditional Chinese painting education, is very focused on research style, through analysis, imitation, innovation, and thus find a suitable for their own, different painting language, a new unique style.

Experience can be divided into direct experience and indirect experience in two forms. A direct experience is a process of experiencing an event, feeling an atmosphere, and generating a particular emotional and cognitive process. This experience is inclusive, omnidirectional, and all senses play a role at the same time. The direct experience is the most basic experience of art activities. The new and unique experience is the prerequisite for artists to create new works, and this experience is mostly derived from our real life. German famous aesthetics Gadamer in another description of the experience of the importance of the arts. He put forward a "experience of art" concept, and that the experience of human experience activities in the main body left a given nature, its content is life. To some extent, the works of art from the artist's experience, is the performance of their experience, art is the art of experience. Chinese painting is very particular about "character as a painting", and many painters from the young age to the old experience, sentiment, to the old side to "people book old" realm. 


\section{The Practical Application of Chinese Traditional Art Education Theory}

The traditional Chinese philosophy culture is profound and is one of the precious spiritual existence of Chinese civilization. As a driving force for the development of modern Chinese culture and education, it still has great historical penetrating power and a solid foundation for equal exchange and dialogue with our world culture. Art education needs modern vision. Is the modern theory of esteem and the traditional culture is not linked to it? Modern hermeneutics founder Heidegger's theory destroyed a simple "modern" superior to "past" and "future" status. It is unrealistic to think that it is unrealistic to leave the past and the future, and that the history and the present fusion become a whole, with no clear boundaries. As Derrida concludes: the presence of imprints of absence. This is not the same as the contemporary German philosophy of Gadharma Moore's view: the modern vision of Fujian and the traditional view of the integration of each other, there is no integration with the traditional as closed, there will not be a whole sense of the modern view of Fujian. Through the study, we can find that the fine traditional Chinese philosophy culture can give the art education theory research to enrich and profound inspiration.

Regardless of which subject of the ultimate goal of education, should be "education students life", art education is no exception. Chinese traditional art education attaches great importance to moral education. At the beginning of the Han Dynasty politician Lu Jia that in moral education, any social education ideals will eventually be implemented to the individual personality training. As an active subject of the individual, its personality is often expressed as active self-conscious self-cultivation process. Lu Jia to moral quality as a concentrated expression of personality, that the understanding of morality is the main content of cognition, lofty moral quality is to guide the understanding of society, the cause of the very achievements of the power.

From the ancient Chinese artisans art education, we are deeply inspired. Artisan art not only enriched the history and culture of the Chinese nation, and this handicraft traditions greatly convey the Chinese people's aesthetics and emotions. I remember Han Meilin in the prose "the most difficult to write two words - the motherland" in a paragraph of the text is very thought-provoking: "National Academy of Fine Arts on the 100, learn are Western mode, three sides without adjustment three space, texture awareness But we are calmly think about it, the Chinese ancient culture for thousands of years, how do not have a Chinese nation, folk art academy and museums, and so on, in addition to Venus, David, and Van Gogh. Hundreds of art institutions are art department, oil painting, prints, Chinese painting ...... and charged with billions of people basic necessities of the practical art design, did not have such a comprehensive art university. Only one more than a dozen Million square meters of the China Arts and Crafts Museum has also become a sales of audio and video and footwear department store.On the only one of the Central Academy of Fine Arts (it is a typical national civil university), but also in some cultural compradors under the instigation of the farmers The son of the city into the city 's reason to sell to the Tsinghua University! These bombarded sandstorms is a fifty - six of our country' s clothing tends to be uniform; so that the national nine hundred and sixty thousand The city of urban planning gradually put on the blue and green glass to the generous building; the city's urban landscape design and urban sculpture are mostly a few pieces of iron film twist, rope around the `stainless steel ball in the head 'sculpture: the national However, the Chinese land, the 10,000 arts and crafts factory in addition to several processing Taiwan, Hong Kong to the goods outside, because there is no, but there is no one, The new design and have closed down, replaced by the country is the cover of the robot, Mickey Mouse, Barbie dolls, wild beans bear such a cultural desertification, do we helpless? World art day, is the world The end of the art of science and technology, finance and trade, the rule of law, system, management, It can be with the advanced world, but the culture and arts emphasize personality, emphasizing national character, independence, reference can not replace.

\section{Conclusion}

Chinese art must have its own modern form, the Chinese nation's art education should be the Chinese people's own characteristics, this is the voice of the times. In today's era, a country, a nation, 
a region, and even a business, the company must establish its own characteristics, the current prevalence of enterprise integration design, that is, CI design, is to highlight the corporate image and characteristics. As the current information becomes more and more convenient, the world becomes smaller and smaller, and when it becomes a global village, self-confirmation is becoming more and more important. Art is the style of originality and uniqueness as a prerequisite, the Chinese art education to the world at the same time will also undergo a further re-self-confirmation process.

\section{References}

[1] Zang Xinming. The characteristics of Japanese Meiji era of art education [J] .America aesthetics. 2013 (06)

[2] Ding Linyi. Peking University Painting Research Association of art education [J]. Popular arts. $2013(04)$

[3] Lu Lu. "Perseverance" and "Progress" of Chinese Painting in the Early Republic of China [J]. Journal of Jiamusi Education Institute 2012 (11)

[4] Zhao Chao Chao. The situation and characteristics of Chinese painting in the early period of the Republic of China [J]. Art Education. 2012 (10)

[5] Li Weiyu. Chinese Movement of the May Fourth Movement and the Change of the Concept of Democracy in the New Culture Movement [J]. Academic Exploration. 2011 (04) 